\title{
Evaluating Hydrothermal System Evolution Using Geochronological Dating and Biological Diversity Analyses
}

\author{
Hidenori Kumagai, Hiromi Watanabe, Takuya Yahagi, Shigeaki Kojima, \\ Shun'ichi Nakai, Shin Toyoda, and Jun-ichiro Ishibashi
}

\begin{abstract}
To elucidate the evolution of hydrothermal activities, we conducted an interdisciplinary study including geochemistry and biology to develop a method of obtaining reliable age information. As geochemical dating techniques, two methods applicable for hydrothermal ore minerals were developed and improved: electron spin resonance method and uranium-thorium disequilibrium method. Cross checks between the two methods generally showed good agreement for the range of hundreds to thousands of years. As biological analysis, the biodiversity among faunal communities in the targeted areas was analyzed at the species and DNA levels. Species and genetic diversity of the local fauna were not always correlated to geochemical dating, either in the southern Mariana Trough region or in the Okinawa Trough region. Although the results are not simple, comparison of age information obtained from analyses of these two disciplines potentially provides important constraints for discussion of the history and evolution of hydrothermal activities.
\end{abstract}

\section{Keywords}

Biodiversity $\cdot$ ESR $\bullet$ Geochronology $\bullet$ Life-span of hydrothermal activity $\bullet$ Mitochondrial mismatch analysis $\bullet$ U-Th disequilibrium

H. Kumagai $(\bowtie)$

Submarine Resources Research Project, JAMSTEC,

Yokosuka, Japan

Institute for Research on Earth Evolution, JAMSTEC, Yokosuka, Japan

Present address: R\&D Center for Submarine Resources, JAMSTEC,

Yokosuka, Japan

e-mail: kumagai@jamstec.go.jp

H. Watanabe

Department of Marine Biodiversity Research, JAMSTEC,

Yokosuka, Japan

Institute of Biogeosciences, JAMSTEC, Yokosuka, Japan

S. Kojima

Atmosphere and Ocean Research Institute, The University of Tokyo, Kashiwa, Japan

Graduate School of Frontier Sciences, The University of Tokyo, Kashiwa, Japan

S. Nakai

Earthquake Research Institute, The University of Tokyo,

Tokyo, Japan

S. Toyoda

Okayama University of Science, Okayama, Japan

T. Yahagi

Graduate School of Frontier Sciences, The University of Tokyo,

Kashiwa, Japan

J.-i. Ishibashi

Submarine Resources Research Project, JAMSTEC,

Yokosuka, Japan

Faculty of Sciences, Kyushu University, Fukuoka, Japan 


\subsection{Introduction}

Deep-sea hydrothermal systems have strongly attracted broad interest from science since their discovery in the late 1970s (e.g. Hessler and Kaharl 1995). The time scale for hydrothermal activity is an important factor to estimate the extent of hydrothermal deposits and the evolutionary process of chemosynthesis-based communities in submarine hydrothermal systems. The chemical flux from hydrothermal systems constrains the supply of substances fostering chemosynthesis-based communities. Therefore, flux intensities affect the biogeochemical reactions and the biological diversities in vent areas. The geochemical diversity observed in vent fluids can be elucidated as a result from scavenging process of the infiltrated seawater, frequently forming impressive chimney structures on the seafloor (e.g. Tivey 1995). Such infiltrated seawater, passing through the subseafloor environment, contains complex biogeochemical ingredients extracted from host formations up to the wider regional scale (e.g. Tsuji et al. 2012). The circulation of hydrothermal systems between seawater and the subseafloor environment has played an important role in the geochemical evolution of the earth. It has provided volatiles and metals that have sustained unique communities and ecosystems in hydrothermal areas from the beginning of Earth's ecosystems (e.g. Rasmussen 2000).

The dating of divergence events and the evolutionary timescale from phylogenetic analysis remains difficult because the molecular clock to estimate a rate of molecular evolution can vary markedly over time and among species. Although a common calibration method of molecular clock is an examination of the fossil record (e.g. Cruzan and Templeton 2000; Smith et al. 2006; Weir and Schluter 2008), fossil evidence of hydrothermal vent communities is rare because of the destruction of vent fauna by hydrothermal activity itself. Other methods of calibrating the molecular clock in gene sequences of hydrothermal vent fauna might be geochronological dating techniques of hydrothermal ore minerals and geological events.

A few studies have been conducted to constrain the lifetime of activity at hydrothermal sites (e.g. Jamieson et al. 2013, and references therein). Such a small amount of constraint is partly attributable to the limited availabilities of numerical dating methods applied to the hydrothermal deposits at inactive sites directly: a gap of $10^{2}-10^{3}$ years (Jamieson et al. 2013). One early trial of geochronology is reported by Lalou et al. (1985). They applied ${ }^{210} \mathrm{~Pb}-\mathrm{Pb}$ and ${ }^{230} \mathrm{Th}-{ }^{234} \mathrm{U}$ disequilibrium method to sulfide deposits collected on and near the ridge axis. The determined ages were as high as 2,100 years. Another trial is on TAG-site, which develops slightly off the MAR-axis in $26^{\circ} 45^{\prime} \mathrm{N}$ (Rona 1984). You and Bickle (1998) reported precipitated age variation within the hydrothermally formed "mound" at the TAG-site, which exceeds $10 \mathrm{ka}$ for core samples obtained in ODP Leg158. Some efforts to generalize these results for ordinary hydrothermal systems have been undertaken for the following reasons: (1) unusually large size of mounds within present-day hydrothermal mounds and (2) the slow spreading environment in which TAG is formed. The former point implies that the duration of the hydrothermalism beneath TAG is unusually long-lived or vigorous or both. Consequently, coupling of methodological challenges to produce reliable age information was conducted for the TAIGA project (Urabe et al. Chap. 1).

Here, the expected life cycle of hydrothermal system ranges from approximately a few years to a few tens of thousands of years. Such a range demands some composite dating protocol for ore minerals. Therefore, we first developed and improved two radiometric dating methods for application to hydrothermal deposits consisting mainly of sulfides and sulfates. Once we achieved such a method, we were able to couple them with ecological analyses to develop a comprehensive analytical protocol to obtain reliable age and duration information related to hydrothermal systems in much broader spectra of hydrothermal activities. For a much longer time range, $>10^{5}$ years, $\mathrm{K}-\mathrm{Ar} / \mathrm{Ar}-\mathrm{Ar}$ methods are applicable. Consequently, in all, the investigated time-span ranged from a few years to a few millions years (Fig. 5.1). The methods developed in our project were applied to two Intensive Survey Sites (ISSs) of the entire "TAIGA" project, of which the results are also reported in this volume (Fujiwara et al. Chap. 34; Ishibashi et al. Chap. 23).

To conduct these studies, the following difficulties to be solved were recognized at the beginning of our project. The first is raised from the phylogeographic aspect. A dearth of precise information related to the molecular evolutionary rates (mutation rate) in genes might cause a discrepancy of interspecies or intraspecies phylogeography. Dispersal and transition events of vent fauna in hydrothermal system are affected strongly by many environmental constraints such as water depths, temperatures, deep-sea currents, and geochemical conditions. Not only calibration methods for such uncertainty but also investigations of life cycles for the vent endemic species must be conducted to produce better phylogeographic information. The latter must be pursued from a geochronological perspective. To obtain reliable numerical ages, a closed system is normally required. However, it is apparently easily disturbed for the samples of ore minerals in the vicinity of the hydrothermal vents. Near active vents, a non-steady and sometimes intermittent supply of vent fluid might occasionally replace the ore minerals once they have been formed. Further abrupt heating influenced by higher temperature fluids might break its closed system, causing a loss of accumulated daughter nuclei or erasure of radiation-related signals used in radiometric dating. These concerns are discussed in later sections. 
Fig. 5.1 Targeted age ranges of respective dating methods

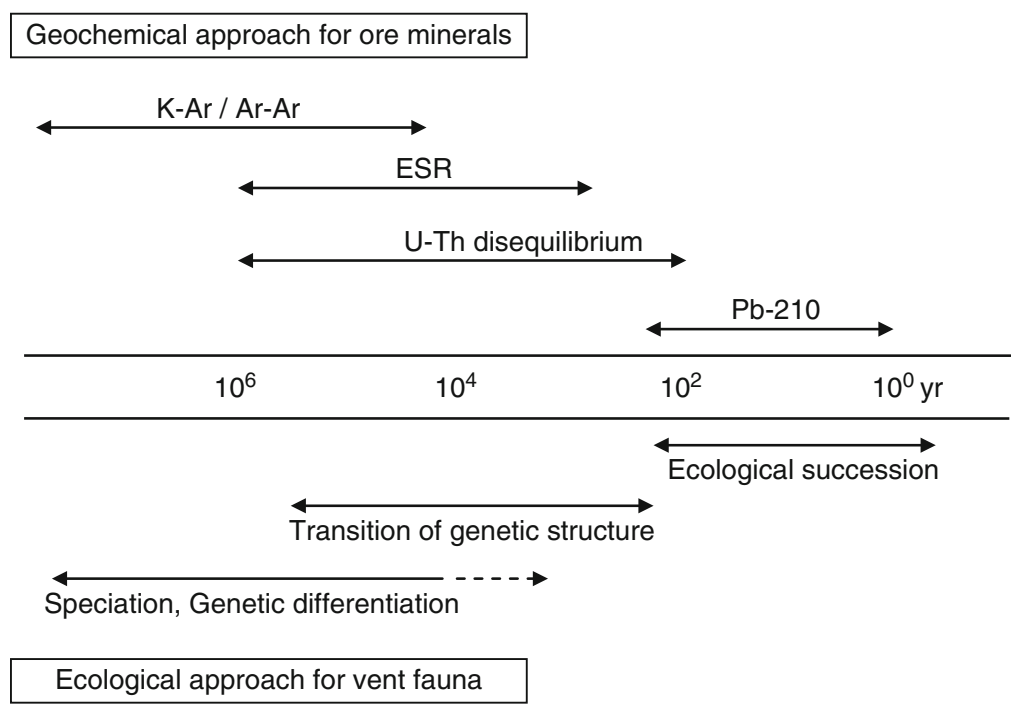

a

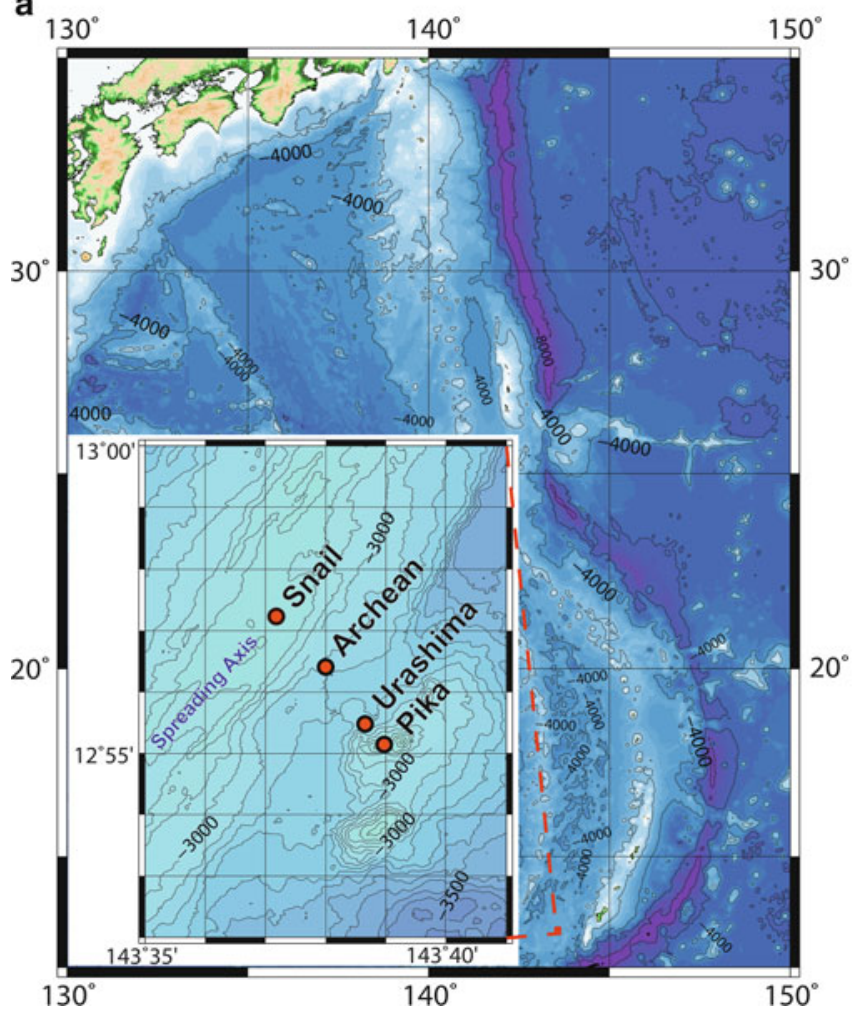

Fig. 5.2 Topographic maps of the studied area according to the global dataset of topography model, ETOPO1 (Amante and Eakins 2009). (a) Southern Mariana Trough. Studied hydrothermal sites and current spreading axis are shown in the inset, with the magnified area shown in red box on main panel. This local topography was obtained by R/V Yokosuka of JAMSTEC, at YK09-08 Cruise. Detailed descriptions are

The targeted areas for this study were two of three focused areas of the TAIGA-project: the Southern Mariana Trough and Okinawa Trough (Fig. 5.2). In these areas, very active hydrothermal activities have been located (Seama et al. Chap. 17; Ishibashi et al. Chap. 29). The

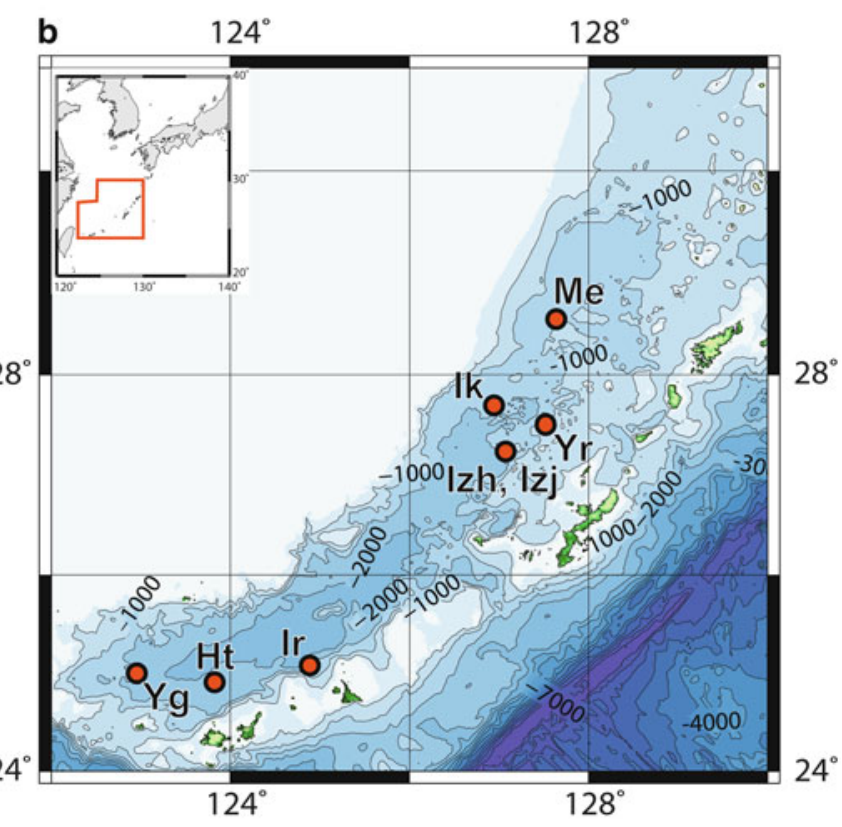

from a report by Seama et al. (Chap. 17). (b) Okinawa Trough. Studied hydrothermal sites are shown as follows: Yg, Daiyon-Yonaguni Knoll; Ht, Hatoma Knoll; Ir, Irabu Knoll; Izh, Hakurei-site in Izena Hole; Izj, JADE-site in Izena Hole; Ik, Iheya North Knoll; Yr, Yoron Hole; Me, Minami-Ensei Knoll. Detailed descriptions were given by Ishibashi et al. (Chap. 29)

third focused area of TAIGA-project, hydrothermal fields in the central Indian Ocean, is unsuitable for this study because only two active sites have been recognized at the beginning of the project (Nakamura et al. Chap. 12). 


\subsection{Development of Dating Methods}

\subsubsection{Geochemical Approach for Ore Minerals}

In our project, two geochronological methods to be applied to the hydrothermal ore minerals consisted mainly of sulfides and sulfates were newly developed: (1) electron spin resonance dating (ESR dating) was applied mainly to barite $\left(\mathrm{BaSO}_{4}\right)$ (Fujiwara et al. Chap. 34; Toyoda et al. 2012), and (2) uranium-thorium disequilibrium dating (U-Th dating) was applied to hydrothermal sulfide minerals consisting mainly of pyrite and sphalerite (Ishibashi et al. Chap. 23; Takamasa et al. 2013). Both methods applied to the samples from the southern Mariana Trough generally showed good agreement in their ages (Fig. 5.3). This issue is discussed in a later section in detail.

Here the ESR-dating is based on the accumulation of unpaired electron in the sample specimen induced by irradiation of high-energy particles and exposure to electromagnetic waves. Such irradiation mainly results from gammaray radiation resulting from the strong attenuation for charged particles in seawater. Consequently, the estimation

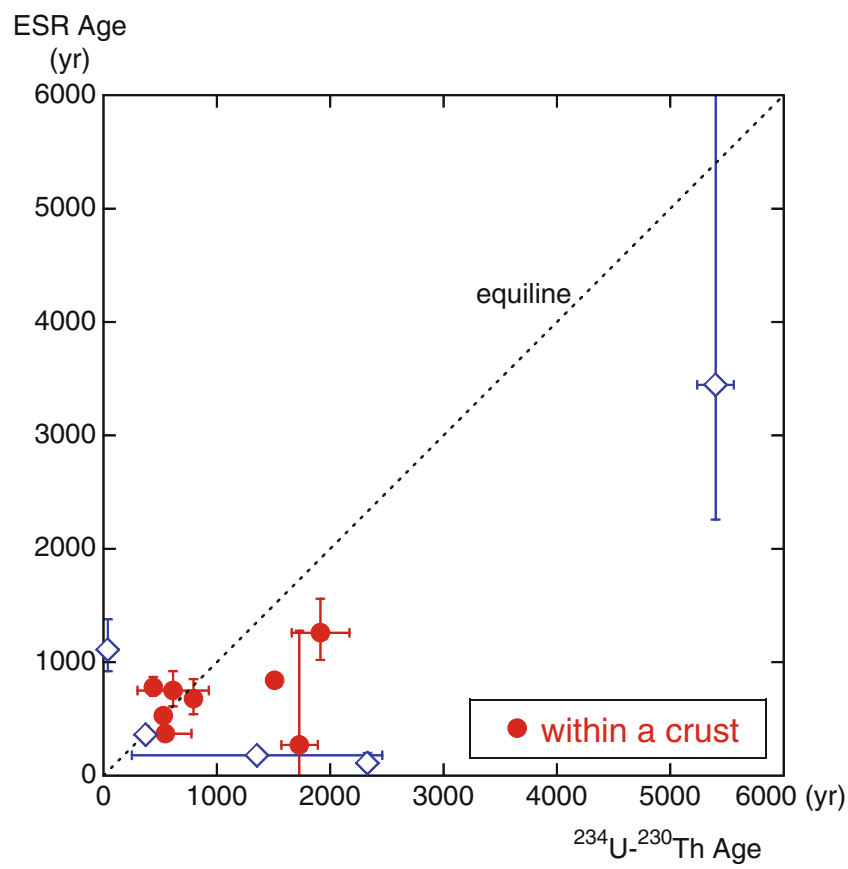

Fig. 5.3 An age comparison obtained using two geochemical methods: U-Th disequilibrium and ESR. Samples used were collected in the Southern Mariana Trough. Aliquots taken from a single crust to check reproducibility of the methods are shown in red circles (Takamasa et al. 2013). Other U-Th data, shown as open diamonds, were taken from a report by Ishibashi et al. (Chap. 23), compared to unpublished ESR data (Fujiwara et al. Pers. Comm.). Here in the case in which the ages obtained from both methods mutually agree, such data are shown on the "equiline" of annual irradiation rate from ore deposits themselves is crucially important to calculate the irradiation age. Where the external radiation was effectively shielded by seawater, an approximation incorporating the internal radiation generated in and around ore precipitates is expected to be sufficient. In addition, ${ }^{226} \mathrm{Ra}$ in barite of a black smoker is unsupported (decaying) because ${ }^{230} \mathrm{Th}$ is negligible in black smokers as a result of its valence and charges, which considerably simplifies the determination of the ages of the target minerals. Here, Ba serves as a proximal stable isotope for $\mathrm{Ra}$ that has no stable isotopes of its own. In fact, ${ }^{226} \mathrm{Ra} / \mathrm{Ba}$ in chimney deposits will decrease as a result of radioactive decay of ${ }^{226} \mathrm{Ra}$ after their formation. Within sulfate minerals, barite was chosen as the target mineral because the obtained signals are clear. To estimate the in-situ dose-rate in a deepsea environment, we calibrated yields of the ESR signals in a known/measured dose-rate as reported by Toyoda et al. (2012). Such a dose rate includes $\alpha$-radiation using an $\mathrm{Al}_{2} \mathrm{O}_{3}$-target. The target tube was deployed near an active vent site in the Mariana Trough and was left for 29 days. Subsequently, it was retrieved for calibration. Details were reported by Toyoda et al. (2012).

The obtained ESR ages from the TAIGA project have also been reported in this volume (Ishibashi et al. Chap. 23; Fujiwara et al. Chap. 34). The determined ages for the samples from the southern Mariana Trough were $1.5 \times 10^{2}-5.3 \times 10^{3}$ years; those from the Okinawa Trough were $4.0-1.6 \times 10^{4}$ years.

The second one is the U-Th dating, which uses the deviation of radioactivity from the radioactive equilibrium. A well known characteristic of the radioactive decay series under secular equilibria is that the specific radioactivities of parent and daughter elements are equivalent. Before reaching this state, i.e. under transient equilibrium, the radioactivity of the daughter element is markedly less than that of the parent nuclei. During our project, a ${ }^{234} \mathrm{U}_{-}{ }^{230} \mathrm{Th}$ system was adopted; respective half-lives ${ }^{230} \mathrm{Th}$ and ${ }^{234} \mathrm{U}$ are $7.6 \times 10^{4}$ years and $2.5 \times 10^{5}$ years. Here, thorium is less soluble in hydrothermal fluids and is not precipitated in hydrothermal minerals, although uranium is precipitated in these minerals. Therefore, ${ }^{230} \mathrm{Th}$ in the mineral simply accumulates from ${ }^{234} \mathrm{U}$ over time, which provides a criterion of the evaluation of data quality. In general, the direct determination is based on the radioactivity measurement, but the radioactivity of the targeted nuclei of the focused system is low because the half life of ${ }^{238} \mathrm{U}$, their ultimate parent, is much longer, $>4.5 \times 10^{9}$ years. Consequently, direct measurements of the abundances of ${ }^{234} \mathrm{U}$ and ${ }^{230} \mathrm{Th}$ were applied in our TAIGA project, which required development of the precise quantification on trace amounts of both ${ }^{230} \mathrm{Th}$ and of ${ }^{234} \mathrm{U}$. Because of the half-lives of our targeted parent-daughter pair, our method can be used to calculate the ages of minerals as young as 50 years when a 
Fig. 5.4 Compiled geochemical ages obtained in Southern Mariana Trough. Original data were reported by Ishibashi et al. (Chap. 23). The Snail site is on the current ridge axis. The distance from the ridge axis is shown as an alternative horizontal-axis in kilometer units

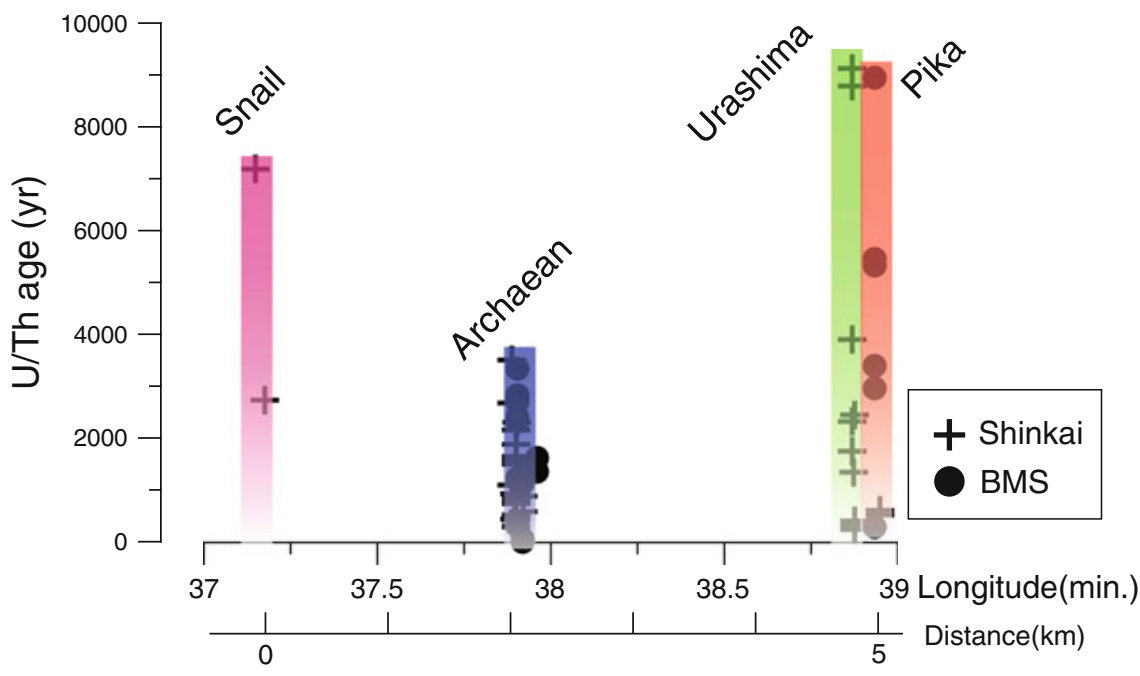

sample contains sufficient uranium but little thorium. However, the upper limit of the range of this dating method is limited to $4.0 \times 10^{5}$ years, which is around eight times the half life of the daughter: ${ }^{230} \mathrm{Th}$.

Detailed protocols of U-Th dating were reported by Takamasa et al. (2013). We analyzed uranium and thorium isotope ratios in mineral specimens using a MulticollectorICP-MS (IsoProbe; GV Instruments Ltd.). The powdered and sieved ore samples were separated electromagnetically using an isodynamic separator to concentrate pyrite and other sulfide minerals. Two mesh ranges were adopted for this study: 100-250 and 250-500 $\mu \mathrm{m}$ (see also Fujiwara et al. Chap. 34). Then, the chemically leached specimens were rinsed, dried, and decomposed using nitric acid. Before the ICP-MS measurements, uranium and thorium were separated from sample solutions under two steps of column chromatography. During this process, barium (Ba) and lead $(\mathrm{Pb})$ were also separated carefully to suppress their interference of signals from targeted isotopes: ${ }^{234} \mathrm{U}$ or ${ }^{230} \mathrm{Th}$.

We determined the ages of hydrothermal deposits samples, with each sample collected by submersible or as a drilled core from the southern Mariana Trough and Okinawa Trough. In the southern Mariana Trough, samples were collected from four sites on and near ridge axis: Snail, Archean, Urashima and Pika sites. The determined U-Th ages were < ca. 7,200 years, ca. 3,500 years, ca. 9,100 years and ca. 9,000 years, respectively (Fig. 5.4). These ranges are shorter than that of the TAG mound (You and Bickle 1998). Here the samples from the Snail site contain low uranium, which raises a concern about a significant loss of uranium from the ore minerals occurring after their formation. Aside from one exceptionally old sample from the Snail site, samples from the Archean site show younger ages than those from the Urashima or Pika sites. This result suggests that the oldest ages from each site are apparently correlated with the distance from the spreading axis in Mariana Trough, at least in off-axis activity (Fig. 5.4). The ESR ages were consistent with the U-Th ages (Takamasa et al. 2013).

In the Okinawa Trough, it is difficult to find such a simple relation with a geographical position of the vent area, e.g. with distance from the spreading axis. The Okinawa Trough is still in the early rifting stage before the normal seafloor/ backarc spreading (Ishibashi et al. Chap. 29 and references therein). Therefore, no clear spreading center is apparent yet. The respective ranges of the determined ages of vent deposits are up to $11,18,144,97$, and $12 \mathrm{ka}$ for DaiyonYonaguni Knoll, Hatoma Knoll, Hakurei-site of Izena-Hole, Iheya North Knoll, and Yoron-Hole (Fujiwara et al. Chap. 34). All ranges include one or two extremely old values, as discussed later. The longest duration of hydrothermal activity was estimated for Hakurei-site of Izena Hole, 16,000 years, even excluding one extreme value. The Izena Hole is a tectonically formed seafloor depression. It might be influenced by rather long activity of the Hakurei-site in the same order of magnitude as that of the TAG mound reported by You and Bickle (1998).

\subsubsection{Comparison between ESR and U-Th ages}

The selected age pairs determined using ESR and U-Th methods for samples from active hydrothermal fields of Southern Mariana Trough are presented in Fig. 5.3. The U-Th ages were obtained from sulfide minerals that had been sieved and magnetically separated (mostly pyrite and sphalerite). The ESR ages were from barite that had been concentrated from sulfide-rich breccia. Some sulfide samples, from the Archean site, are also analyzed using the ESR method for cross-checking. The ages obtained using the two methods mostly show a correlation in the 
diagram. Both ages are well matched down to the order of hundreds of years $\left(\sim 10^{2}\right.$ years). This time range is well within the range of the vent complex consisting of several feed paths in the particular field. Although the reason causing the discrepancy remains unclear, the ESR ages tend to be lower than U-Th ages in the case of Southern Mariana sulfides (Fig. 5.3). This phenomenon might be the result of the robustness of a closed-system of each method. Here ESR signals might be reset by thermal disturbances, whereas U-Th ages might be disturbed by the dissolution or the adsorption of targeted isotopes.

To interpret the obtained ages, special caution for extremely old U-Th ages should be discussed. One remarkable case is that of a sample from the Snail site in the southern Mariana Trough. The old U-Th age was obtained from only one very-low-U sample, $<50 \mathrm{ppb}$ of ${ }^{238} \mathrm{U}$ at the site (Ishibashi et al. Chap. 23). This low U concentration suggests a loss of uranium after their precipitation, which is apparently consistent with much younger ESR ages determined at the site up to 110 years. It might be result of acidic fluid recurrence to minerals once precipitated, where oxidized uranium becomes soluble again. In the Okinawa Trough, more than five samples also contain such low uranium. However, extreme U-Th ages remain for all sites (Fig. 5.5). Another possibility is sediment contamination during and after formation of the analyzed deposits. For further comparison with ecological information, extreme ages of all the sites should be treated carefully. Therefore, in the Okinawa Trough, age ranges are up to the 16,000 year, as shown in colored bars in Fig. 5.5.

\subsubsection{Ecological Analyses of Vent Fauna}

The estimation for evolutionary processes of hydrothermal activities has been done using three biological features: (1) species diversity of vent fauna, (2) genetic diversity of a population, and (3) speciation events (Fig. 5.1). The species diversity fluctuates in the change of habitat conditions. In the case of hydrothermal systems, drastic ecological succession starts from a newly created vent site or a sterilized site after volcanic eruption (Govenar 2010; and references therein). The first majority of inhabitants at this primary stage includes thermophilic prokaryotes (Lutz et al. 1994; Shank et al. 1998). Planktonic larvae or adults of vent-specific faunal species migrate from other vent areas, settle on a suitable niche, and gradually make a large and complex-structured faunal aggregation with high diversity of species. Therefore, high species diversity was only observable in continuous vent fields. Species diversity of vents conveys the short-scale fluctuation of vent activity.

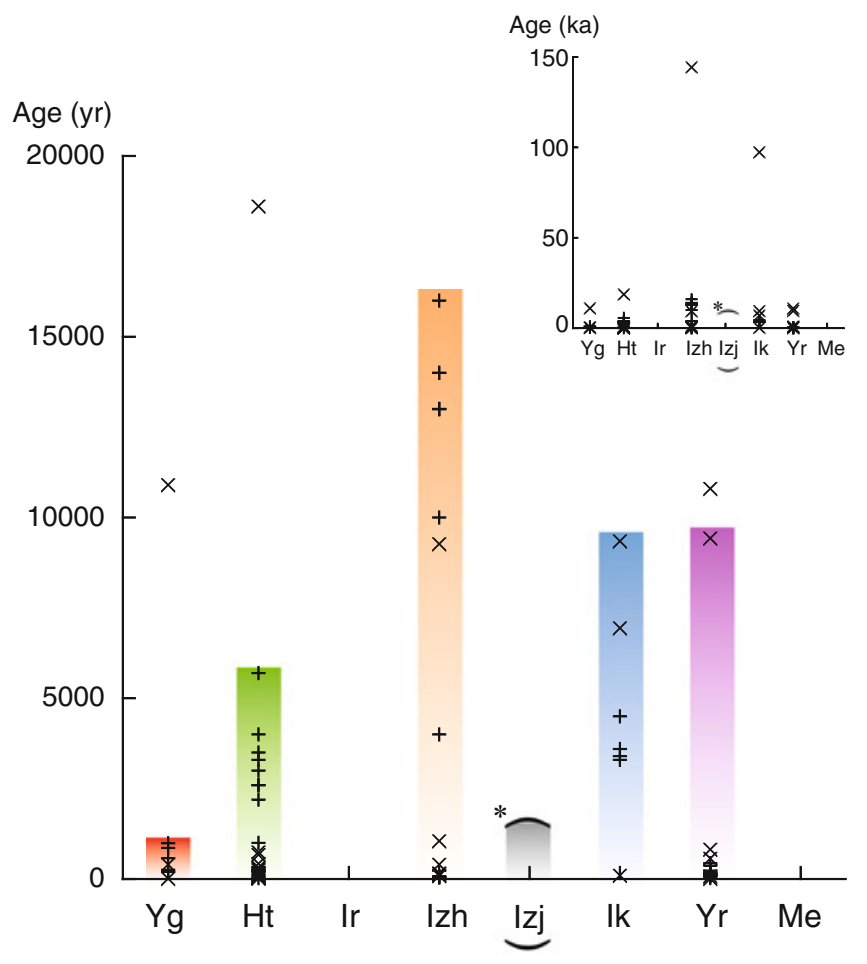

Fig. 5.5 Geochemical age range determined from the sulfide and sulfate deposits in Okinawa Trough. Active sites are shown from approximately SW to NE. The left-hand side is the southwestern end. Here, all obtained ages including extremely old two values are shown in the inset. Colored bars represent reliable age ranges for respective sites. The localities are denoted as described for Fig. 5.2b. Age data of JADE site in Izena Hole were not obtained in this study. Consequently, the data range is in parenthesis and denoted by a "*” symbol (Zeng et al. 2009)

Once an organism settles in a suitable environment of the vent field, the demographic expansion of the fauna begins. The genetic diversity of a population should be correlated positively with its effective population size (number of individuals involved in reproduction), and it is regarded as tracer of past demographic expansion of a population (Rogers and Harpending 1992). Therefore, the genetic diversity of a population can be an estimator of the past population expansion after settlement of vent species, or formation of a vent environment that is suitable for the species. The temporal change of genetic variation can be examined using a molecular clock hypothesis, which has been used to estimate divergence times. The molecular clock hypothesis states that DNA and protein sequences evolve at a mutation rate, which is constant over time and among populations. For example, the partial sequence of mitochondrial cytochrome oxidase c subunit I (COI) gene, which is commonly used as a barcode of species, has been investigated. Reportedly $1.4 \%$ sequence divergence per $10^{6}$ years occurred on the gene sequence of snapping shrimp (Knowlton and Weigt 1998). However, the rates of accumulation of genetic variation are not the same among 
Fig. 5.6 Number of species collected at active hydrothermal sites in the southern Mariana Trough

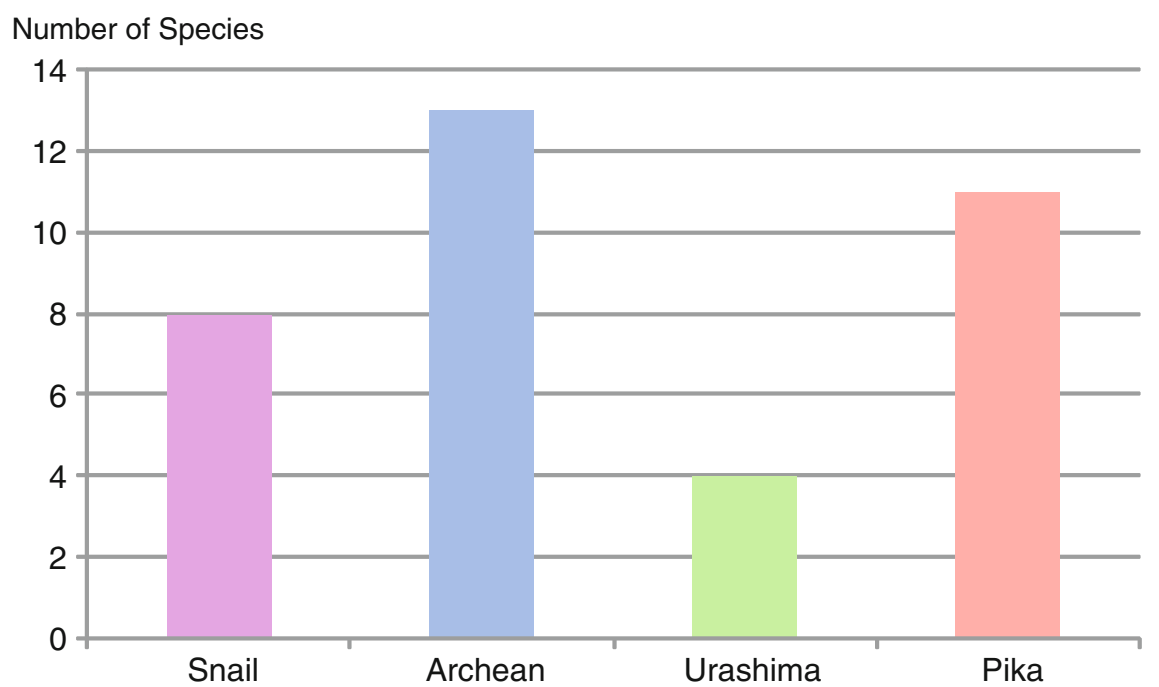

species (e.g. large animals have lower genetic diversity than small ones; Beebee and Rowe 2008), and the dating of vent activity with genetic diversity can only provide relative ages for many species.

The expanded population might be divided into two or more subpopulations either sympatrically or allopatrically. Without gene exchange or connectivity among the subpopulations, genetic differentiation accumulates and eventually causes speciation, which is an irreversible event. With calibration of the molecular clock, speciation ages of some vent animals have been estimated in million year order with geologic events (Shank et al. 1999; Johnson et al. 2006, 2010). Estimation of the speciation date of vent species provides the longest scale.

To investigate the relation between biodiversity described above and hydrothermal activity, we examine the dataset of species diversity as well as genetic diversity based on partial COI sequences of vent species in the southern Mariana Trough and the Okinawa Trough.

In the Southern Mariana Trough, six active hydrothermal sites have been found in all. Four sites, located linearly across the spreading axis, were specifically examined in this study. In these four sites, the fauna associated with the Archean sites accounted for the largest number of species (Fig. 5.6), which implies that the present vent-related community of the Archean site has a longer history than those of other three sites, even though the number of species was almost half of those in the Central Mariana Trough (see Kojima and Watanabe Chap. 26). In addition, the evenness or relative abundance is important to assess the biodiversity and community structure. Nevertheless, no quantitative analysis has been reported in this area. The Archean site develops at the greatest water depth $(2,990 \mathrm{~m})$ among the four Southern Mariana sites between the current spreading axis and an off-axis seamount. The biodiversity of the particular vent field might depend partly on the water depth developed, although differences in sampling efforts or temporal changes might also affect the results. Comparison of genetic diversity as a mismatch distribution (Fig. 5.7), which describes mismatches among paired sequences in a population consisting of a single species, shows the difference of relative ages of population expansion. Alviniconcha gastropods and Neoverruca barnacles clearly show the greater genetic diversity with greater distances from the ridge axis (Fig. 5.7a, c). However, Chorocaris shrimps showed two peaks in their mismatch distribution (Fig. 5.7b) reflecting their complex history in the southern Mariana Trough vent fields, such as population subdivision and re-connection. Using a molecular marker with higher resolution capability than the COI gene, such events were also shown to have occurred for Alviniconcha gastropods in the Mariana Trough (Hidaka et al. Chap. 27). This evidence might show some events such as decrease of hydrothermal activity in the Mariana Trough about 1 Ma: details are presented by Hidaka et al. (Chap. 27).

In the Okinawa Trough, a comprehensive investigation of vent fauna with quantitative sampling and geochemical measurements was conducted as a part of TAIGA project. The faunal list in the vent fields in the Okinawa Trough was updated (Watanabe et al. Chap. 40). The number of species recorded is the highest in vent fauna in the Minami Ensei Knoll, although it is low in the Yoron Hole and Irabu Knoll (10 and 14, respectively; Fig. 5.8). These two sites were discovered recently (Fukuba et al.; Chaps. 47 and 48). Additional surveys should be conducted to confirm this result. Otherwise, they were actually newly established hydrothermal activities. The fauna might be represented by rapidly colonized species. Indeed, one representative of these fauna, Shinkaicaris leurokolos, shows high genetic diversity in all examined vent fields, 
Fig. 5.7 Genetic divergence of COI gene indicated as mismatches in base sequences among three vent endemic species in the Southern Mariana Trough. Scale bars are shown as five mismatches of partial COI sequences
Number of mismatches of COI

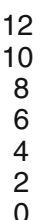

a. Alviniconcha hessleri

- 5 mismatches

2
8
6
4
2
0
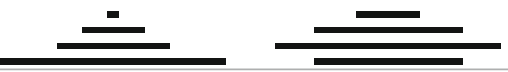

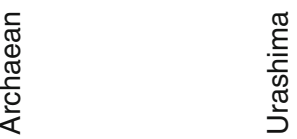

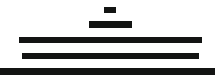

$\overline{\widetilde{\sigma}}$
क

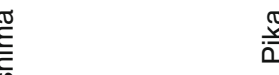

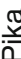

12
10
8
6
4
2
0

b. Chorocaris vandoverae

5 mismatches

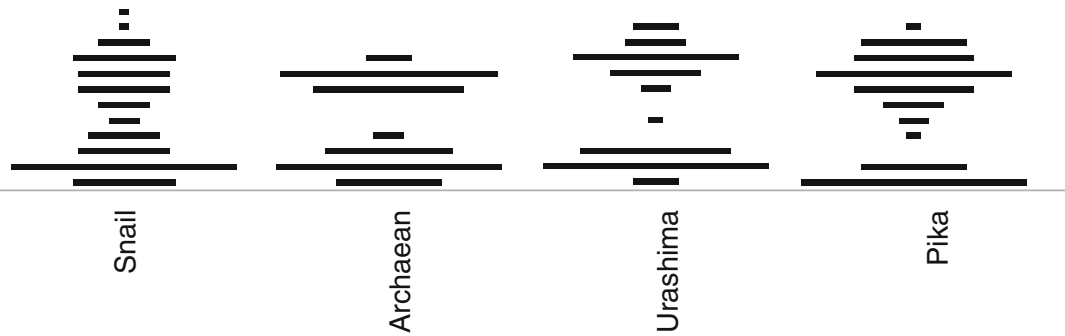

C. Neoverruca brachylepadoformis

5 mismatches
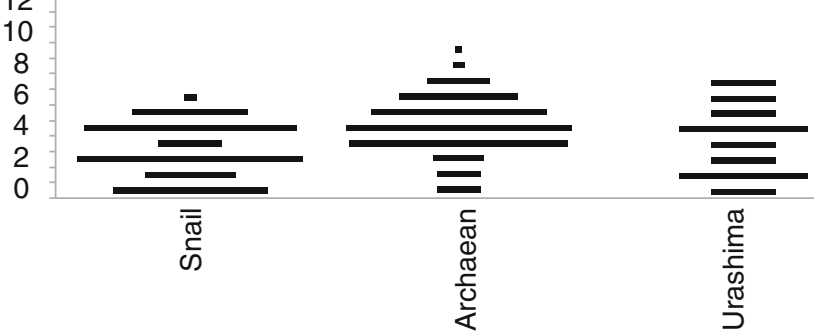

$\stackrel{\widetilde{\pi}}{\frac{\pi}{2}}$

Number of Species

Fig. 5.8 Numbers of species collected at active hydrothermal sites in Okinawa Trough. Localities are denoted as described for Fig. 5.2b

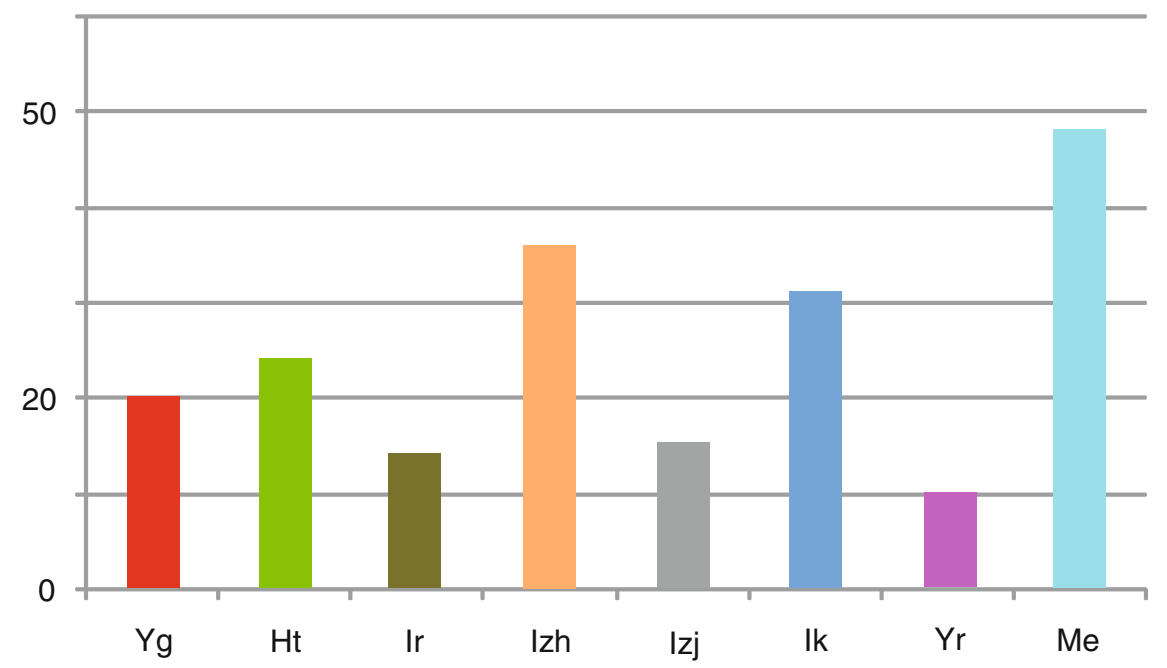

implying high fecundity in a short period because genetic diversity is generated only in embryonic production and because life-history strategies strongly affect genetic diversity (Fig. 5.9). This aspect will be discussed in the next section through comparison with geochemical dating results. 


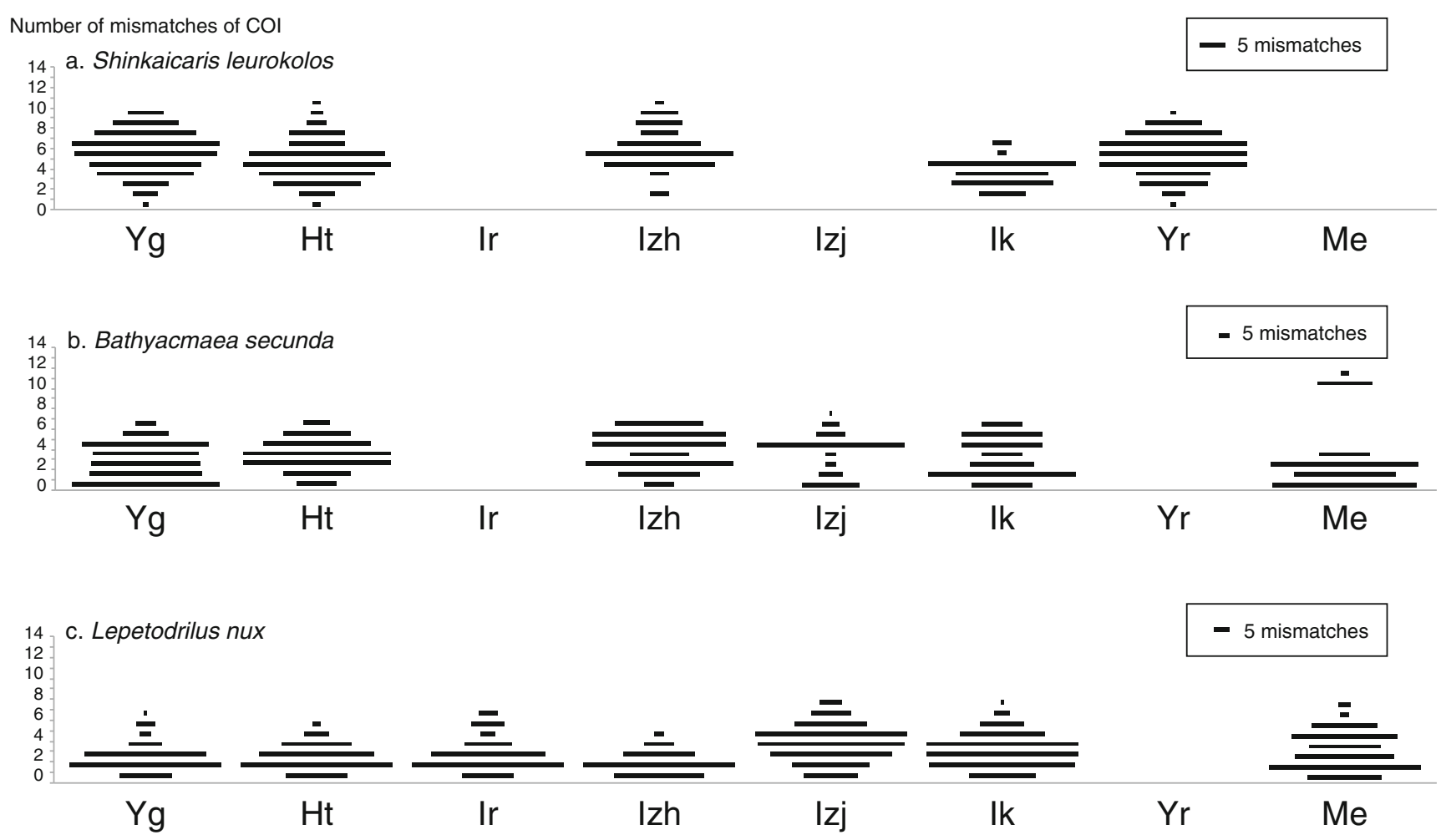

Fig. 5.9 Genetic divergence of COI gene indicated as mismatches in base sequences among three vent endemic species of the Okinawa Trough. (a) Shinkaicaris leurokolos, (b) Bathyacmaea secunda, (c) Lepetodrilus nux. Localities are shown as in Fig. 5.2b. Scale bars are shown as five mismatches of partial COI sequences

\subsection{Comparisons Between Ecological and Geochemical Age Information}

As a challenge to estimate the evolution history of hydrothermal system in the aspect of the relations between geochemical environment and ecological responses, a comparative analysis of the chronological information obtained both from geochemical dating and from ecological analyses was conducted.

Results obtained from two different approaches were not simply comparable even under a simple geographical setting in the southern Mariana Trough. From the geochemical data, the ages of the hydrothermal sites composed of multiple vents were fairly correlated with the distance from the present day's spreading center where the seafloor is newly formed, which implies that the durations of the faunal communities could be longer in the distant vent field from the spreading axis. However, that inference is not fully supported by the ecological approach. The vent endemic communities might be severely damaged or exterminated if the older vent field experienced later eruption or seafloor renewal by lava flows. Such is not the case of an observed reversal in the numbers of species between Archean and Urashima/Pika sites because such seafloor renewal is not implied at the Urashima/Pika site, but it is at the Archean site, as indicated by high magnetization (Fujii et al. 2013). Another complexity is apparent from the genetic diversity at the Snail site: it is as large as those at the other three sites (Fig. $5.7 b, c)$. This point is partly supported by the rather old age, up to $7.2 \mathrm{ka}$, at the Snail site, although only one exceptional datum shows such an old age. In contrast, a phylogeographical approach suggests a $0.2-1.0 \mathrm{Ma}$ history for populations in the area (Hidaka et al. Chap. 27). This discrepancy has yet to be investigated.

Furthermore, a complicated situation was observed in the Okinawa Trough. Bathyacmaea secunda as a vent endemic species showed greater genetic diversity at the Hakurei site in the Izena Hole, which was indicated as the number of mismatches of the COI sequences (Fig. 5.9b). It is apparently consistent with the longer life of the vents at the Hakurei site estimated as exceeding $16 \mathrm{ka}$ from geochemical data. However, genetic diversities of the Shinkaicaris at Daiyon-Yonaguni Knoll were as great as those at Yoron Hole, although their ranges of geochronological ages were different. They were also considerably younger than results show for the Hakurei-site (Figs. 5.5 and 5.9a). This point might be explained by the high-larval dispersal potentials of the species, resulting in a higher rate of gene flow among local populations. In terms 


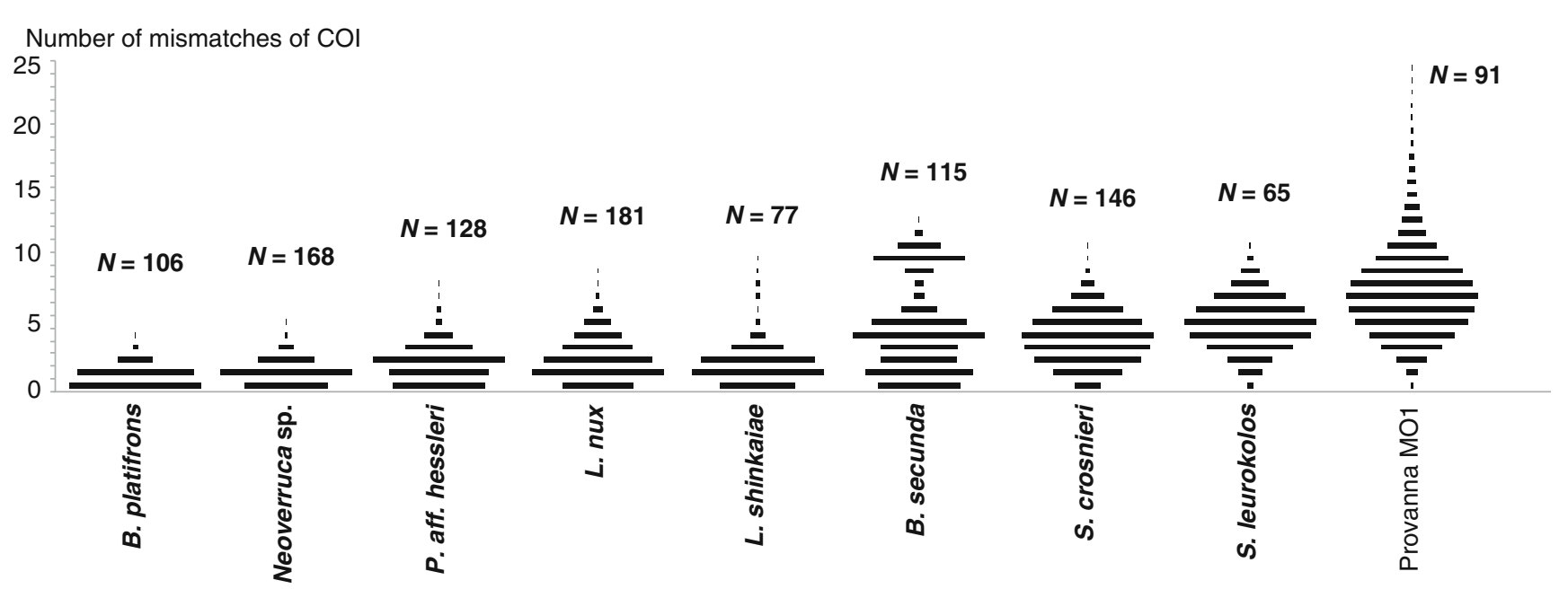

Fig. 5.10 Genetic mismatch diagram of COI gene sequences for typical faunal species in Okinawa Trough. This diagram shows entire variations for each species counted in the Okinawa Trough; the analyzed number of individuals is shown as $N$

of the inter-species comparison, the trend in genetic diversities of local populations of two limpets Bathyacmaea secunda and Lepetodrilus nux differed. Higher genetic diversity was observed in the southern populations in Bathyacmaea secunda, but lower genetic diversity was observed in the same ranges of populations in Lepetodrilus nux (Fig. 5.9b, c). Ecological features of vent faunas are necessary for more precise estimation of biological and geological histories of vent fields.

The trends of diversity are also different among species, even for similar animals inhabiting areas that are close to each other (Fig. 5.10). This result indicates that the genetic diversities of the species positioned on the right-hand side develop quickly. However, those of species on the left-hand side develop slowly. In other words, the variety of genetic diversity means that we have a series of scales with several ranges of resolution. Among the analyzed species shown in Fig. 5.9, Shinkaicaris leurokolos is the species for which the quickest genetic substitution is expected: all analyzed sites showed uniformly high diversities. However, such diversity has not developed among the slowest species: Lepetodrilus nux. Among these three, the intermediate, Bathyacmaea secunda, might adequately reflect the ages of the hydrothermal vent sites, which is apparently consistent with geochronological results, even including extremely old ages (Fig. 5.5). According to the genetic diversities of Shinkaicaris leurokolos and Bathyacmaea secunda, the estimated ages of populations are on the order of $10^{4}$ years, which corresponds well to the ranges inferred using a geochronological approach.

Ecological information will help to interpret these results of phylogeographic analyses and will be useful to estimate the ages of hydrothermal vent sites in the Okinawa Trough. Even for the same vent sites, inhabitants show various levels of genetic diversity, which are expected to correspond to their ecological characteristics. Consequently, ecological information of respective species on their life-history strategies, including reproduction and larval dispersal ability, are necessary to interpret genetic diversity of faunal populations and for application to estimate the history of hydrothermal activity.

\subsection{Conclusions}

The duration of present-day hydrothermal activities estimated from geochemical dating of ore minerals has approximately up to a few tens of thousands of years as reliable maxima in the Okinawa Trough and in the Southern Mariana Trough as back-arc tectonic settings. This duration is apparently in the same order of magnitude of duration as the TAG mound activity under the slow spreading condition of Mid-Atlantic Ridges. The results of ecological analyses presented herein showed various genetic structures among species, although they inhabit the same vent fields. Whereas populations of some species simply increase their genetic diversity along with the duration of hydrothermal activity, those of others show no such relation. Consequently, we can expect to select adequate species for dating the activities based on the genetic population structure of vent-endemic species. Correspondence to results obtained using geochemical dating will offer a useful evaluation criterion for the selection of the adequate species.

Acknowledgements All maps were tabulated using GMT software, a free mapping tool (Wessel and Smith 1998). This study was supported by the "TAIGA project," which was funded by a Grant-in-Aid for Scientific Research on Innovative Areas (KAKENHI, No. 20109004) from the Ministry of Education, Culture, Sports, Science and 
Technology (MEXT), Japan. The final stage of this study was also supported by Submarine Resources Research Project, JAMSTEC. Constructive comments by three reviewers, Prof. H. Hyodo of Okayama Univ. Sci. and Drs. K. Sato and H. Yamamoto of JAMSTEC, greatly improved this article.

Open Access This chapter is distributed under the terms of the Creative Commons Attribution Noncommercial License, which permits any noncommercial use, distribution, and reproduction in any medium, provided the original author(s) and source are credited.

\section{References}

Amante C, Eakins BW (2009) ETOPO1 1 arc-minute global relief model: procedures, data sources and analysis. NOAA Technical Memorandum NESDIS NGDC-24, National Geophysical Data Center, Boulder, Colorado, p 19

Beebee T, Rowe G (2008) An introduction to molecular ecology. Oxford University Press, Oxford, p 400

Cruzan MB, Templeton AR (2000) Paleoecology and coalescence: phylogeographic analysis of hypotheses from the fossil record. Trend Ecol Evol 15:491-496

Fujii M, Okino K, Honsho C, Dyment J, Florent S, Mochizuki N (2013) Developing near-bottom magnetic measurements using a 3D forward modeling technique: application to hydrothermal vent fields. In: Proceedings of international symposium on underwater technology 2013, presented in international symposium on underwater technology 2013, March 2013, Tokyo, Japan

Govenar B (2010) Shaping vent and seep communities: Habitat provision and modification by foundation species. In: Kiel S (ed) The vent and seep biota: aspects from microbes to ecosystems. Springer, New York, pp 403-432

Hessler RR, Kaharl VA (1995) The deep-sea hydrothermal vent community: an overview. In: Humphris SE et al (eds) Seafloor hydrothermal systems. Geophysics Monograph Series, vol 91. American Geophysical Union, Washington, D.C., pp 72-84

Jamieson JW, Hannington MD, Clague DA, Kelley DS, Delaney JR, Holden JF, Tivey MK, Kimpe LE (2013) Sulfide geochronology along the endeavour segment of the Juan de Fuca ridge. Geochem Geophys Geosyst 14(7):2084-2099. doi:10.1002/ggge.20133

Johnson SB, Young CR, Jones WJ, Warén A, Vrijenhoek RC (2006) Migration, isolation, and speciation of hydrothermal vent limpets (Gastropoda; Lepetodrillidae) across the Blanco Transform fault. Biol Bull 210:140-157

Johnson SB, Warén A, Lee RW, Kano Y, Kaim A, Davis A, Strong EE, Vrijenhoek RC (2010) Rubyspira, new genus and two new species of bone-eating deep-sea snails with ancient habits. Biol Bull 219:166-177

Knowlton N, Weigt LA (1998) New dates and new rates for divergence across the Isthmus of Panama. Proc R Soc Lond Ser B Biol Sci 265:2257-2263
Lalou C, Brichet E, Hekinian R (1985) Age dating of sulfide deposits from axial and off-axial structures on the East Pacific Rise near $12^{\circ} 50^{\prime} \mathrm{N}$. Earth Planet Sci Lett 75(1):59-71

Lutz RA, Shank TM, Fornari DJ, Haymon RM, Lilley MD, Von Damm KL, Desbruyeres D (1994) Rapid growth at deep-sea vents. Nature 371:663-664

Rasmussen B (2000) Filamentous microfossils in a 3,235-million-yearold volcanogenic massive sulphide deposit. Nature 405:676-679

Rogers AR, Harpending H (1992) Population growth makes waves in the distribution of pairwise genetic differences. Mol Biol Evol 9:552-569

Rona PA (1984) Hydrothermal mineralization at seafloor spreading centers. Earth Sci Rev 20(1):1-104

Shank TM, Fornari DJ, Von Damm KL, Lilley MD, Haymon RM, Lutz RA (1998) Temporal and spatial patterns of biological community development at nascent deep-sea hydrothermal vents $\left(9^{\circ} 50^{\prime} \mathrm{N}\right.$, East Pacific Rise). Deep Sea Res II 45:465-515

Shank TM, Black MB, Halanych KM, Lutz RA, Vrijenhoek RC (1999) Miocene radiation of deep-sea hydrothermal vent shrimp (Caridea: Bresiliidae): evidence from mitochondrial cytochrome oxidase subunit I. Mol Phylogenet Evol 13:244-254

Smith AB, Pisani D, Mackenzie-Dodds JA, Stockley B, Webster BL, Littlewood DTJ (2006) Testing the molecular clock: molecular and paleontological estimates of divergence times in the Echinoidea (Echinodermata). Mol Biol Evol 23(10):1832-1851

Takamasa A, Nakai S, Sato F, Toyoda S, Banerjee D, Ishibashi J (2013) U-Th radioactive disequilibrium and ESR dating of a baritecontaining sulfide crust from South Mariana Trough. Quat Geochronol 15:38-46. doi:10.1016/j.quageo.2012.12.002

Tivey MK (1995) Modeling chimney growth and associated fluid flow at seafloor hydrothermal vent site. In: Humphris SE et al (eds) Seafloor hydrothermal systems. Geophysics Monograph Series, vol 91. American Geophysical Union, Washington, D.C., pp 158-177

Toyoda S, Sato F, Nishido H, Kayama M, Ishibashi J (2012) The alpha effectiveness of the dating ESR signal in barite. Radiat Meas 47:900-902

Tsuji T, Takai K, Oiwane H, Nakamura Y, Masaki Y, Kumagai H, Kinoshita M, Yamamoto F, Okano T, Kuramoto Si (2012) Hydrothermal fluid flow system around the Iheya North Knoll in the midOkinawa trough based on seismic reflection data. J Volcanol Geotherm Res 213-214:41-50

Weir JT, Schluter E (2008) Calibrating the avian molecular clock. Mol Ecol 17:2321-2328

Wessel P, Smith WH (1998) New, improved version of the generic mapping tools released. EOS Trans Am Geophys Union 79:579

You CF, Bickle MJ (1998) Evolution of an active sea-floor massive sulphide deposit. Nature 394:668-671

Zeng Z, Yu S, Yin X, Wang X, Zhang G, Wang X, Chen D (2009) Element enrichment and U-series isotopic characteristics of the hydrothermal sulfides at Jade site in the Okinawa Trough. Sci China Ser D Earth Sci 52(7):913-924 